\title{
Women Participation in Organizational Activities in a Democratic Society as Perceived by Stakeholders' in North-West Nigeria.
}

\author{
SARKINFADA Halima Ph. D, HUSSAINI Manir \\ Educational Foundations Department \\ Faculty of Education and Extension Services Usmau Danfodiyo University Sokoto \\ College of Agriculture Zuru Kebbi State Nigeria PM B 1018
}

\begin{abstract}
The study assessed women participation in organizational activities in a democratic society as perceived by stakeholders' in North-West Nigeria. The research design that was used for this study is the descriptive survey design The design allows for the use of questionnaires, which generated valid data that were analyzed. The population of this study consisted of all the stakeholders in education that comprised the students, graduates, teachers, school administrators, Ministry personnel, Quality Assurances officers in the North-west zone of Nigeria. The target population consisted of all stakeholders in the following states: Sokoto, Zamfara, and Kano in the North-west zone of Nigeria. Multi-stage sampling technique was adopted needed for this study. The total population of stakeholders in North-west Nigeria was 1,970 out of this numbers, 1261 respondents were proportionately selected for the study. Two research questions were raised as follows: (1) What are the stakeholders" perception of the influence of women participation in organizational activities in North-west Nigeria. (2). What are the stakeholders' perception of empowering women to engage in politics an enduring democracy in North-west Nigeria. The findings of this study revealed that more than half of the stakeholders perceived the influence of WCCE graduates on participation in organizational activities in North-west, In addition the result also indicated that more than half of the stakeholders perceived the contributions of graduates of WCCE to graduates empowerment in politics in North-west, The study recommended that Women were adjudged by the respondents as organizers of homes, and families. Therefore women graduates participation in organization activities in their communities should double their effort so as to continue to serve as a role model to other women in the society for socio-economic development.. NGOs and State government should provide additional support for women to have access to loans and market facilities. Providing them with soft loans would be required.
\end{abstract}

Key Words: Women, Organizational Activities, Democratic Society Stakeholders, Perception

\section{Introduction}

Women education, according to Mangvwat (1999) is thus perceived as one of the indicators that could be used to measure the level of social development of the nation. It is closely related with most of the demographic variables such as infertility, child mortality, mother and child care, population growth rate and acceptance of family planning. Educated women are more likely to raise children who are healthier and are likely to stay longer in school and are better. Such women Mangvwat further maintained that they reinforce their daughters educational aspirations. Omolewa (2002) agreed with Haruna (2001)said that an educated woman is in a better position to appreciate the culture of her people. Such a woman according to Omolewa can differentiate her culture from foreign ones; she can distinguish between good from bad cultural values. An educated woman is in a better position to protect and promote the socio-cultural values of the society in which she lives. 
It is generally recognized today that the education of girls and women as the one provided by Women Centre for Continuing Education is one of the wisest profitable investment in social economic terms. The benefits are numerous. The first person to benefit from education is the women or girl as an individual and as member of society. But the positive effects are felt also by the family husband, children, the community, society and the whole country. As the saying goes 'Educating a boy is educating a person, educating a girl is education a Nation'. A woman with knowledge is a respectable woman, she has the power to make people listen to her and her charisma makes people work with her.

Raney (1995 8) listed 10 advantages of women education as follows;

a. Women who are educated are more able to influence their future .

b. Women who are educated are able to reduce poverty.

c. Women who are educated reduces the risk of child mortality.

d. Women who are educated are 50\% more likely to have their child immunized.

e. Women who are educated are less likely to be taken advantage of less to contact HIV//AIDS.

f. Women who are educated are less likely to become victim of domestic or sexual abuse.

g. Women who are educated reduce corruption and change the conditions that lead to terrorism.

h. Women who are educated are better equipped to contribute to the family income.

i. Women who are educated are healthier and tend to have greater self esteem and self confidence.

j. Women who are educated help contribute and prosper their community.

Boson (2009) enumerated the benefit of women Education in terms of the girl as an individual, the family: community and society, and Nation as follows:

The girl as individual: Education leads to greater self-esteem and self confidence, and opens new horizons for girls, enabling them to discover their own potential, to develop themselves fully and increase their resistance to gender discrimination,

The family: Durkheim (1956) enplaned that Education helps girls and women to have a positive impact on their families: better childcare (vaccination, schooling etc) better nutrition, decrease in child mortality better communication with the children and other family members. A recent study shows that the decrease in child malnutrition between 1970 and 1995 is attributed to the tune of 44\%; to improvement in female education. Bonvilla (2003), concluded that women's education is combined with an improvement in their status which account for their active participation societal activities. An educated woman is better equipped to increase family income and resolve family problems satisfactorily, her family's wellbeing thus pets a big boost to her career.

The community and Society: Education heightens women's awareness of the important role they can play in the community and society to find solutions to problems that impede development and social stability. Survival rates schooling and community productivity increase as a result of women's education with a corresponding decrease in another and infant mortality rates.

The community and society thus become more prosperous. The Nation: with awareness of her role citizen, and educated woman can play a more dynamic role in addressing the economic challenges faced by her country, in the areas of agricultural production, food self fulfilling prophecy, the fight against environmental degradation, the use and conservation of water and energy. Education alone is obviously not enough to solve the world's problems, but it remains an essential factor in any development activities.

All through history, women have occupied a very significant proportion in human society In Nigeria for instance, the Federal Republic of Nigeria 2006 census revealed that women constitute 68,293,683 which is about half of the population of the country. It is not amazing that from time immemorial women have been regarded as partners in progress to men. The United Nations (1994) described women as home makers and centres of the family. They are also the main custodians of socio-cultural and fundamental values of the society and permanent change is often best achieved through them. As child bearers, women occupy a very sensitive position in the society.

\section{Statement of the Problem}


Despite the numerous benefits accruing from the participation of the women on various organizational activities to the communities and the nation at large, Sarkinfada (2017) study reveals that there are factors that constrain the empowerment of women in these activities. Such factors may include: Lack of relevant education, gender inequality, lack self perceived self-esteem, and others perceived self esteem. In a democratic society women are perceived as irrelevant in organizational activities irrespective of the role played by women. In a democratic society women are seen as having low level of education householdburden, husband influence, corruption and the likes are among the factors constraining women empowerment and participation in organizational activities. This is in accordance with the observation of the Kwesiga (1999) who noted that participation of women in democratic and organizational activities at all levels is hampered by factors such as limited resources, lack of government assistance, lack of training and educational opportunities, cultural values and discrimination against women.

\section{Conceptual Clarifications \\ Research Questions}

This study provided answers to the following research questions:-

1. What are the stakeholders perception of the influence of women participation in organizational activities in North-west Nigeria.

2. What are the stakeholders perception of empowering women to engage in politics an enduring democracy in North-west Nigeria.

\section{Objectives of the Study}

The general purpose of this study is to find out stakeholder's perception of empowering women for socioeconomic development in an enduring democracy in North-west Nigeria. The following are stated to help address the study, specifically :

1. To investigate the stakeholders perception of the influence of women participation in organizational activities in North-west Nigeria.

2. To investigate the stakeholders perception of empowering women to engage in politics an enduring democracy in North-west Nigeria.

\section{Methodology}

The research design that was used for this study is the descriptive survey design The design allowed for the use of questionnaires, which generated valid data that were analyzed. The population of this study consisted of all the stakeholders in education that comprised the students, graduates, teachers, school administrators, Ministry personnel, Quality Assurances officers in the North-west zone of Nigeria. The target population consisted of all stakeholders in the selected states in the zone. Multi-stage sampling technique was adopted for the selection of the sample needed for this study. The total population of stakeholders in North-west Nigeria was 1970 out of this numbers, 1261 respondents were proportionately selected for the study. This is in agreement with the Research Advisor (2006) sample size table (see appendix I) as it was recommended that in a population of 1970 at confidence level of $95 \% .1261$ respondents could be appropriately sampled. Four states were selected out of the seven North-western states using purposive sampling technique.

The following instrument was used for the study, a questionnaire titled "Questionnaire on the Contributions of Women Centres for Continuing Education to Socio-economic Development (QCWCCESED). The instrument was developed by the researcher. QCWCCESED had two sections. Section A contained items that elicit information on respondents demographic data while section B contained items that elicited information on the contribution of Graduates of WCCE to the organizational activities and Political empowerment of women as perceived by stakeholders.

The validity of the instrument was ascertained using content validity technique. This approach was used to ensure if the items of the questionnaire corresponded with the focus of this study. to ascertain the reliability of the questionnaire, a pilot study was conducted using one centre that is Jigawa State Adult and non-formal 
learning centre at Dutse, which is within the studied area, but not used by the researcher for this study. A reliability coefficients are: 0.70 was obtained.

\section{Results}

RQ1: What are the stakeholders perception of the influence of women participation in organizational activities in North-west Nigeria.

Table 1: Stakeholders' Perception of the Influence of WCCE on Graduates Participation in Organizational Activates in North-west, Nigeria

\begin{tabular}{|l|r|r|}
\hline Perceived Participation & Frequency (f) & Percentage (\%) \\
\hline Very Low & 147 & 11.7 \\
\hline Fairly Low & 416 & 33.0 \\
\hline Moderate & 511 & 40.5 \\
\hline High & 187 & 14.8 \\
\hline Total & 1261 & 100.0 \\
\hline
\end{tabular}

Source: Field work 2017

Table 1 shows the stakeholders' perceived influence of WCCE graduates participation in organizational activities in North-west, Nigeria. The results show that 147(11.7\%) of the stakeholders' perceived the influence of graduates of WCCE on participating in organizational activities as very low participation, 416 (33.0\%) perceived such as fairly low, 511 (40.5\%) perceived the participation as moderate while $187(14.8 \%)$ of the stakeholders perceived their participation as high. It can therefore be concluded from this result that while $511(40.5 \%)$ of them perceived the participation as moderate, 187(14.8\%) of stakeholders perceived the participation of graduates of WCCE in organizational activities in the North-west, Nigeria as high, noticing it was moderate participation. The specific stakeholders' analysis is further presented in Table 2.

Table 2: Analysis of Stakeholders' Perception of the Influence of WCCE Graduates Participation in Organizational Activities in North-west, Nigeria

\begin{tabular}{|l|r|r|r|r|r|r|}
\hline \multirow{2}{*}{ Stakeholders } & \multicolumn{7}{|c|}{ Perception } \\
\cline { 2 - 7 } & $\begin{array}{r}\text { Very } \\
\text { Low }\end{array}$ & \% & Moderate & \% & Total & Rank \\
\hline Students & 56 & 39.7 & 85 & 60.3 & 141 & 5 th \\
\hline Graduates & 30 & 30.6 & 68 & 69.4 & 98 & 2nd \\
\hline Teachers & 64 & 39.3 & 99 & 60.7 & 163 & 4 th \\
\hline School Administrators & 15 & 27.8 & 39 & 72.2 & 54 & 1 st \\
\hline Ministry Personnel & 35 & 31.8 & 75 & 68.2 & 110 & 3rd \\
\hline Quality Assurance Officers & 363 & 52.2 & 332 & 47.8 & 695 & 6th \\
\hline Total & 563 & & 698 & & 1261 & \\
\hline
\end{tabular}

Source: Field work 2017

Table 2 shows in summary the specific stakeholders' analysis of perception of the influence of WCCE graduates participation in organizational activities in North-west, Nigeria. It is shown that $56(39.7 \%)$ of the students perception of the influence of WCCE graduates participation in organizational activities in North-west, Nigeria as very low, 85(60.3\%) perceived the participation as Moderate, with a total of 141 students. The students perception rank 5th among all the stakeholders, 30(30.6\%) of the graduate of WCCE perceived the participation as very low, and 68(69.4\%) of the graduates perceived participation as moderate. With a total of 98 graduates. 
The graduates perception rank 2nd among all stakeholders. 64(39.2\%) of the teachers perceived participation as very low and $99(60.7 \%)$ of teachers perceived the participation as moderate, with a total of 163 teachers. The teachers perception rank 4th in the perception of stakeholders. 15(27.7\%) of school administrators perceived the participation as very low and 39(72.2\%) of school administrators perceived the participation as moderate, with a total of 54 school administrators. The school administrators perception rank 1st among the stakeholders. 35(31.8\%) of ministry personnel perceived the participation as very low, and $75(68.2 \%)$ of ministry personnel perceived the participation as moderate with a total of 110 of ministry personnel.

RQ2: What are the stakeholders perception of empowering women to participate in politics in an enduring democracy in North-west Nigeria.

Table 3: Stakeholders' Perception of the Contributions of Graduates of WCCE to Graduates Empowerment in North-west Nigeria

\begin{tabular}{|l|r|r|}
\hline $\begin{array}{l}\text { Stakeholders' Perceived } \\
\text { Contribution }\end{array}$ & Frequency (f) & Percentage (\%) \\
\hline Poor contribution & 127 & 10.1 \\
\hline Fair Contribution & 423 & 33.5 \\
\hline Good Contribution & 551 & 43.7 \\
\hline Very Good Contribution & 160 & 12.7 \\
\hline Total & 1261 & 100.0 \\
\hline
\end{tabular}

Source: Field work 2017

Table 3 shows the stakeholders' perception of the contributions of graduates of WCCE to graduates empowerment in North-west, Nigeria. The results show that 127(10.1\%) of the stakeholders' perceived the contributions of graduates of WCCE to graduates empowerment as poor contribution, 423(33.5\%) perceived such contributions as fair, 551(43.7\%) perceived the contributions as good, while 160(15.3\%) of the stakeholders described such contributions as very good. Indication is further shown from this result that more than half $711(56.4 \%)$ of the stakeholders perceived the contributions of graduates of WCCE to graduates empowerment in North-west, Nigeria as good. The individual stakeholders' analysis is further presented in Table 16

Table 4: Analysis of Stakeholders' Perception of the Contributions of Graduates of WCCE to Graduates Empowerment in North-west, Nigeria

\begin{tabular}{|c|c|c|c|c|c|c|}
\hline \multirow[b]{2}{*}{ Stakeholders } & \multicolumn{5}{|c|}{ Perception } & \multirow[b]{2}{*}{ Rank } \\
\hline & Poor & $\%$ & Good & $\%$ & Total & \\
\hline Students & 57 & 40.4 & 84 & 59.6 & 141 & 5 th \\
\hline Graduates & 30 & 30.6 & 68 & 69.4 & 98 & $1 \mathrm{st}$ \\
\hline Teachers & 64 & 39.3 & 99 & 60.7 & 163 & 4th \\
\hline School Administrators & 18 & 33.3 & 36 & 66.7 & 54 & 2nd \\
\hline Ministry Personnel & 42 & 38.2 & 68 & 61.8 & 110 & $3 \mathrm{rd}$ \\
\hline Quality Assurance Officers & 339 & 48.8 & 356 & 51.2 & 695 & 6th \\
\hline Total & 550 & & 711 & & 1261 & \\
\hline
\end{tabular}

Source: Field work 2017

Table 4 shows in summary the specific stakeholders' analysis of stakeholders perception of the contributions of graduates of WCCE to graduates empowerment in North-west Nigeria It is shown that $57(40.4 \%)$ of the students perceived the contributions of graduates of WCCE to graduates empowerment in North-west, Nigeria. as poor, $84(59.6 \%)$ perceived the contributions as good, with a total of 141 students. The students perception rank 5th among all the stakeholders, 30(30.6\%) of the graduate of WCCE perceived the contributions as poor, and $68(69.4 \%)$ of the graduates perceived contributions as good. With a 
total of 98 graduates. The graduates perception rank 1st among all stakeholders. $64(39,3 \%)$ of the teachers perceived contributions as poor and $99(60.7 \%)$ of teachers perceived the contributions as good, with a total of 163 teachers. The teachers perception rank 4th in the perception of stakeholders. 18(33.3\%) of school administrators perceived the contributions as poor and $36(66.7 \%)$ of school administrators perceived the contributions as good, with a total of 54 school administrators.

\section{Discussion of Findings}

The findings of this study revealed that more than half of the stakeholders perceived the influence of WCCE graduates on participation in organizational activities in North-west, Nigeria as either moderate or high. It is a known fact that education promotes enlightment as well as individual level of awareness of the happenings not only in his/her immediate environment but globally. Bonvilla (2003), concluded that women's education is combined with an improvement in their status which account for their active participation societal activities. An educated woman is better equipped to increase family income and resolve family problems satisfactorily. Omoruyi, and Omiunu, (2006)). Ibrahim (2008), asserted that despite the huge financial resource spent on education by the government, the truth of the matter is that there are several hidden norms and folkways, that affects women participating in politics and organizational activities in Nigeria. is not supported by the findings in this study. Findings from this study rather upholds the perception that WCCE graduates on participation in organizational activities as high.

Awareness could be considered as a necessary condition for participation. Education heightens women's awareness of the important role they can play in the community and society to find solutions to problems that impede development and social stability. Considering the important position women occupy in the society, Mangvwat (1999) opined that the educated woman should be allowed to use their potentials in social development of the nation. Their education has also closely related with most of the demographic variables such as infertility, child mortality, mother and child care, population growth rate and acceptance of family planning. Individual's interest in participating in organizational activities is further enhanced through education and as a result of their literacy level, graduates of women centres are better equipped than before. Education changes status and boosts self-esteem.

In addition the result also indicated that more than half of the stakeholders perceived the contributions of graduates of WCCE to graduates empowerment in politics in North-west, Nigeria as either good or very good. Considering the current economic situation in the country and all over the world, the issue of empowerment usually dominates any economic discussion in Nigeria. This can only be achieved if individual members of the society including women are able to contribute their quotas to economic development. This also supports the findings of Nwosu (2008) study on education for all women by year 2015. Women centre for continuing education Sokoto. Nigeria. She found out that with all the benefits of the centre, some families still find it difficult to allow their wives to utilize the skills acquired through meaningful employment.

In any society where the women constitute a reasonable percent of the entire population leaving them behind in the scheme of economic emancipation could be a cog in the wheel of the society economic breakthrough. The need for creating avenue for women emancipation has attracted global attention and education has been recognized globally as veritable tool to achieve this purpose. The establishment of women centres for continuing education across the states in the North-west, Nigeria has been one of the of Government commitment for the essence of women's emancipation for socio-economic development.

This finding buttresses Anyebe (2001) that feminists have advanced the issue of empowerment of women through education as means of challenging patriarchal ideology of domination and women subordination transforming the structures and institutions that perpetuate gender discrimination and social inequality as well as creating equal opportunity for women at all levels in all spheres of human endeavour. Durosaro (2016) stressed that women did not achieve their innate potentials maximally because of a psychological barrier which tended to inhibit them from striving for achievement; but challenging patriarchal attitude has pave way for women involvement. Empowerment of women as well as women contributing their respective quotas through graduate empowerment which consequently from WCCE in the North-west would enable 
them to engage in small scale enterprise, which is one of the ways of reducing the incidence of poverty and unemployment among women.

\section{Conclusion}

Conclusively, more of the stakeholders perceived the influence of graduates of women centres for continuing education on participation in organizational activities in North-west, Nigeria as commendable and forthcoming. However, teachers, Quality assurance and students scored the influence of graduates of women centres for continuing education on participation in organizational activities in North-west, Nigeria lower than other stakeholders.

It was also observed that more than half of the stakeholders perceived the contribution of women centres to graduates empowerment in North-west, Nigeria as large extent. Perceptions of stakeholders such as graduates of the centres, school administrators, and Ministry personnel on these responsibilities were more favourable than the other stakeholders. On the contrary Quality Assurance Officers, students and teachers of the centres perceived otherwise.

\section{Recommendations}

1. Women were adjudged by the respondents as organizers of homes, and families. Therefore women graduates participation in organization activities in their communities should double their effort so as to continue to serve as a role model to other women in the society for socio-economic development..

2. Stakeholders perceived the contribution of women centres to graduates empowerment in North-west, Nigeria as very good. NGOs and State government should provide additional support for women to have access to loans and market facilities. Providing them with soft loans would be required.

\section{References}

[1] Anyebe, A. A (2001): Reading in Development Administration, Zaria, Shereef Salam Press.

[2] Bonvilla, V. (2003). Feminization and matriculation of Education superiority. Feminization of Higher Education in Puerto Rico. A journal of proceedings in Puerto Rico, International conference. 2(1), 12-19

[3] Bown, L. \& Okedera, L.T. (1981). An Introduction to the Study of Adult Education. Ibadan University Press Ltd. Bride more hope . Igbo Women in socio-economic change. Pp 49-63. Institute of African studies, University of Nigeria. Nsukka. Nsukka. 2008.

[4] Durkheim, E. (1956). Education and sociology. Glence Illinois Free Press.

[5] Durosaro, I. A. (2016). Patriarchal attitudes; Counseling as an effective intervention. Being a paper presented at 164th Inaugural lecture delivered at the University of Ilorin, Ilorin Nigeria.

[6] Haruna, M. J. (2001). The Relationship between marital Status and Academic Achievement of Female Students in Shehu Shagari College of Education, Sokoto. Unpublished postgraduate project, pp. 45-48.

[7] Ibrahim, B.A (2008). Challenges on girl Child Education in Nigeria, Unpublished Paper presented at UNICEF Conference in Kano.

[8] Mangvwat, J. A. (1999). The Benefits of Education for women and Girls Education in Nigeria. Jos: Arrow Head Communications Limited.

[9] Nwosu, N. P. (2008). Education For All Women by Year 2015. Women Centre for Continuing Education Sokoto Nigeria. As case study. A paper presented at International conference Millennia 2015, Women Actors for Development for Global Challenges Belgium.

[10] Omolewa. M. (2002). "Education" in Africa Atlases (Nigeria) Paris-Frances, Les Editions J. A. pp. 115-118.

[11] Omoruyi, E. F. O. \& Omiunu, S. E. (2006). Strategies for strengthening continuing education programmes for the attainment of equal access to education by 2015.Nigeria national council for adult education (NNCAE) 13(7), 116 - 125.

[12] Ramey, C. (1995). Women and higher education. Trends and Perspectives, Women higher Education comparative perspective American, Kuwer Academic Publishers. 
[13] United Nations (2014). United Nations Report on Women and Girls Education. http/:www.UN.education/efa/global.cocomprehensive.efa. 